\title{
Low Level Laser Therapy in the Treatment of Temporomandibular Joint - (Short Review)
}

\author{
Ahmad Khaled Alhakim ${ }^{1 *}$, Nabeel Abo Kashreef ${ }^{2}$, Nawras Maher Mostafa ${ }^{3}$, Shady Ahmed Moussa ${ }^{4}$ \\ ${ }^{1}$ Oral and Maxillofacial Surgery Specialist, PHCC, Qatar \\ ${ }^{2}$ Otolaryngologist Specialist, PHCC, Qatar \\ ${ }^{3}$ Restorative \& Advanced Aesthetic Dentistry and endodontics, Iraq (PHCC, Qatar) \\ ${ }^{4}$ Consultant and Lecturer of Pediatric Dentistry \& Oral Public Health Department, Zagazig University, Egypt
}

DOI: $10.36347 /$ sjams.2022.v10i01.002

| Received: 29.11.2021 | Accepted: 01.01.2022 | Published: 04.01.2022

*Corresponding author: Ahmad Khaled Alhakim

Oral and Maxillofacial Surgery Specialist, PHCC, Qatar

\section{Abstract}

Temporomandibular disorder (TMD) is a collective term, characterized by symptoms involving muscles of mastication, TMJ and orofacial structures resulting from a dysfunction of the stomatognathic system. Temporomandibular disorders (TMDs) which considered the major cause of non-dental facial pain, involve a wide range of symptoms in masticatory muscles and temporomandibular joints (TMJ). Diagnosis is usually delayed due to the multifactorial etiology, and the lack of assessment devices and parameters. The Low-Level Laser LLLT is a noninvasive, quick and safe, non-pharmaceutical intervention that may be beneficial for patients with TMDs. However, the clinical efficiency of LLLT in the treatment of this kind of disorders is controversial. Low-level laser is considered a phototherapeutic alternative method, like the low-level laser, as an effective source for stimulating the anti-pain signals in the tissues due to their low-level waves and energies. The low-level lasers might cause the increased beta-endorphin content, decreased both bradykinin and histamine levels, and increased lymphatic flow to decreased inflammatory factors and the decreased pain-related factors. Conclusion: This review suggests that LLLT effectively relieves pain and improves functional outcomes in patients with TMD.

Keywords: Temporomandibular disorder (TMD), etiology, Diagnosis, LLLT.

Copyright ( 2022 The Author(s): This is an open-access article distributed under the terms of the Creative Commons Attribution 4.0 International License (CC BY-NC 4.0) which permits unrestricted use, distribution, and reproduction in any medium for non-commercial use provided the original author and source are credited.

\section{BACKGROUND}

Temporomandibular disorders (TMD) is a collective term for pain and dysfunction of the masticatory muscles and temporomandibular joints (TMJs). Its most common features are regional pain in the face and preauricular area, limitations in jaw movements, and noises from the TMJs during jaw movements [1]. The most common types of TMD include pain-related disorders (e.g., myalgia, headache attributed to TMD, and arthralgia) and disorders associated with the TMJ (primarily disc displacements and degenerative diseases) [2] Chronic pain is the overwhelming reason for seeking TMD treatment, while TMD may also be associated with impaired general health, depression, or other psychological disabilities that affect the patient's wellbeing and quality of life [3]. TMD shares similarities with other chronic pain conditions such as chronic tension-type headache or migraine, low back pain, and fibromyalgia and causes much suffering for the individual [4]. In
1934, the dental profession was generally first drawn into the area of TMDs with an article written by Dr. James Costen [5]. He was an otolaryngologist who, based on eleven cases, first suggested to the profession that changes in the dental condition were responsible for various ear symptoms. In the late 1940s and into the 1950 s, the dental profession began to question bite raising appliances as the therapy of choice for mandibular dysfunction [6, 7]. Early scientific studies suggested that the occlusal condition could influence masticatory muscle function. Electromyographic studies were used to correlate such relationships [8-10].

\section{Epidemiology}

Reports indicate the prevalence of TMD in the population to be about $10-15 \%$ for adults and $4-7 \%$ for adolescents [11, 12]. Incidence reports for adults meeting a TMD-pain diagnosis were $3.9 \%$ and for selfreported TMD-pain in adolescents, $4.6 \%[13,14]$. The condition affects women more frequently than men and is most common in the child-bearing years (20-40 
Ahmad Khaled Alhakim et al; Sch J App Med Sci, Jan, 2022; 10(1): 9-14

years), with a decrease in distribution with age. In adults, the gender ratio is approximately 2:1 (women: men) in population-based studies and $4: 1$ or more among clinical cases of TMD pain [15]. There are no gender differences in children, but with increasing age during adolescence to young adulthood, the sex ratio increases to approximately $2: 1$ (girls: boys) $[15,16]$. In a longitudinal study in adults, $49 \%$ of the incident cases reported persistent pain when re-examined six months later [17]. Similarly, in a longitudinal study of adolescents, $45 \%$ reported TMD pain once a week or more when re-examined 10-12 years later [18].

\section{Laser Biostimulation}

Since the first postulation of the principle governing the emission by stimulation by Albert Einstein in 1917, the laser light technology has flared in leaps and bounds. The Laser biostimulation was introduced in 1966 by Endre Mester in Budapest for the first time [19, 20]. It's also called LLLT (Low Level Laser Therapy) which is the application of light (usually delivered via a low power laser or light-emitting diode; LED) to promote tissue repair, reduce inflammation or induce analgesia. It uses the action of light and light alone to directly stimulate host cells in order to reduce inflammation, relieve pain and/or promote wound healing by using visible red to near-visible infrared (IR) part of the electromagnetic spectrum [21]. LLLT, first published by Andre Mester, is the application of light, usually a low power laser to a pathology to promote tissue regeneration, reduce inflammation and relieve pain. The light is typically of narrow spectral width in the red or near infrared spectrum $(600-1,000 \mathrm{~nm})$, with a power density (irradiance) between $\left(1 \mathrm{~mW}-5 \mathrm{~W} / \mathrm{cm}^{2}\right)$. It is typically applied to the injury for a minute or so, a few times a week for several weeks. Unlike other medical laser procedures, LLLT is not an ablative or thermal mechanism, but rather a photochemical effect comparable to photosynthesis in plants whereby the light is absorbed and exerts a chemical change [22].

\section{Mechanisms of Low-Level Laser Therapy}

LLLT mechanism of action explained by light absorption within the mitochondria [21-23]. The cells can contain up to several thousand mitochondria, which generate cellular energy (ATP) from oxygen and pyruvate. In Stressed or ischemic tissues, mitochondria synthesize nitric oxide (mtNO) which competes and can displace oxygen from binding to Cytochrome c oxidase (CcO) which is the terminal enzyme in the electron transport chain necessary for energy generation $[21,24$, 25]. Two negative effects result: reduced ATP synthesis and increased oxidative stress (leading to inflammation via activation of the inflammatory "master switch" The transcription factor NF- $\mathrm{KB}$ ) [21, 26-28]. LLLT biostimulation follow the Arndt-Schulz law and according to this law low-dose will increase physiologic processes, and strong stimuli will inhibit physiological activity [29]. In some patients the goal inhibition rather than stimulation, especially for pain management. High doses of laser light will inhibit the pain signals, partially by creating transient varicosities along the neurons, impeding signal transmission. It has been reported opioid-related mechanism as well as reduction of action potential, selective inhibition of $\mathrm{A} \delta$ and $\mathrm{C}$ fibers, and suppression of noxious stimulation [30-32]. In acute pain is a decrease of the level of PGE2 and other inflammatory markers. Direct inhibition of peripheral afferent terminals suppresses peripheral sensitization and limits further release of neurokinins but when immediate pain reduction is the therapeutic goal, energies as high as 50 to $100 \mathrm{~J}$ may be needed $[30,33]$ using inhibitory doses to decrease neural transmission. In chronic pain, sensitization is more important than inflammation. Sensitized peripheral nociceptors may gradually be desensitized by repeated irradiation at lower energies because the Low-level laser doses are cumulative that's mean in chronic conditions should be treated only once or twice weekly while the acute conditions treated until resolve. Usually, the low-level lasers do not cause temperature elevation within the tissue, but rather produce their effects from photobiostimulation effect within the tissues. Low-level lasers do not cut or ablate the tissue. The therapy performed with low-level lasers is called as LLLT or therapeutic laser therapy, and this therapy has been referred as biostimulation and biomodulation [30]. The output powers for LLLT range from 50 to $500 \mathrm{~mW}$ with wavelengths in the red and near infrared of the electromagnetic spectrum, from 630 to $980 \mathrm{~nm}$ with pulsed or continuous-wave emission. Biostimulatory effect of laser irradiation is determined by the magnitude of the absorbed light energy. Energy depth of penetration depends on factors such as wavelength, optical and temperature characteristics, power, energy values, exposure time, wave shape, and optical characteristics of tissue-absorption and scattering coefficient. LLLT has an anti-inflammatory effect, it shortens the inflammatory process. The irradiation with 635-nm and existing COX inhibitors inhibits expression of COX and PGE2 release, decrease in reactive oxygen species (ROS) levels and mRNA expression of cytosolic and secretory phospholipase A2 (cPLA2 and sPLA2) and reduced TNF- $\alpha$ levels in acute inflammation, that's lead us to conclude the antiinflammatory effect of LLLT seems to be a good alternative to the NSAIDs (Non-Steroidal AntiInflammatory Drugs) that give similar results but without drugs side effect. However, the steroids reduce the anti-inflammatory effect of LLLT [30, 34, 35]. Temporomandibular disorder (TMD) is a collective term including number of clinical problems that involve the masticatory musculature, the temporomandibular joint (TMJ) and associated structures, or both. The use of LLLT as method of non-surgical treatment of TMD with several advantages over other methods because of LLLT non-invasive, cost effective and does not have any known side effect. For arthritis the superficial head of the mandible (caput mandibulae) is an easy target for any wavelength in this area the overdosage is more 
Ahmad Khaled Alhakim et al; Sch J App Med Sci, Jan, 2022; 10(1): 9-14

likely than underdosage ( 2 to $3 \mathrm{~J}$ around the caput is sufficient), to reduce the inflammatory process the repeated dose is needed in this case [12, 36, 37]. For muscular problems high doses if irradiation is needed in case of sever trismus (40 to $50 \mathrm{~J}$ ). However low doses needed after surgery to prevent trismus. Usually IR light, 6 to $10 \mathrm{~J}$ per point applied tender points and reduced tenderness indicates the desired process has been initiated and dose need to be pain free. Also clinically we can observed the LLLT effect in the form of bite strength increase range of motion, and muscular relaxation [30, 38-41]. (Nabeel Sayed et al., 2013) [42] tried to investigate the efficacy of low level laser therapy (LLLT) in the treatment of temporomandibular disorders (TMD) in relation to pain intensity, tender points, joint sounds and jaw movements, they found There was a rapid decrease in the pain intensity; the number of tender points and joint sounds and there was no relapse of the disease during the follow up period, that's making the $s$ the use of LLLT as an alternative to other conventional treatment modalities in TMDs by producing positive outcomes. The effectiveness of lowlevel laser therapy in the treatment of temporomandibular disorders in both myogenic and atherogenic cases was studied by (Kulekcioglu S et al., 20013) [43] both patient groups (active and placebo) in this study received LLLT, they found: Significant reduction in pain was observed in both active and placebo treatment groups and there was no significant difference between myogenic and atherogenic cases regarding the treatment effect. These results making placebo-controlled study has supported the use of LLLT as an alternative to other conventional treatment modalities in TMD of myogenic and atherogenic origin. The effectiveness of LLLT in TMD patients also evaluated by (Lassemi E et al., 2008) [44] they found that LLLT was effective in management of TMD signs and symptoms with considerable reduction or elimination of pain severity and clicking. The consensus about the mechanism of LLLT effects inevitably involves mitochondria. The effects of HeNe laser and other illumination on mitochondria isolated from rat liver have included increased proton electrochemical potential, more ATP synthesis, increased RNA and protein synthesis and increases in oxygen consumption, membrane potential, and enhanced synthesis of NADH and ATP. This photo stimulatory effect in mitochondria processes enhanced growth factor release and ultimately led to cell proliferation [22, 23, 49].

\section{Low Level Laser Therapy and Temporomandibular Disorders}

Dentists play an important role in the treatment of TMJ arthralgia, which contributes to improve the patient's quality of life. The choice of treatment should be based on the assessment of each case. The obtained results showed that the association of LLLT and piroxicam was not more effective than single therapies in the treatment of TMJ arthralgia, and all the treatments were effective in decreasing pain. In the 30 - day follow-up, the use of piroxicam was more effective than the use of LLLT [44]. TMD has a direct impact on patient quality of life because it is commonly related to pain and loss of quality of the stomatognathic system functions [46]. PBMT using low-power lasers has been widely indicated for the management of musculoskeletal disorders due to its analgesic, antiinflammatory, and regenerative effects, and because it is a noninvasive therapy without side effects [47, 48]. We expect the use of photo biomodulation with LEDs, infra and red, to reduce pain, improve temporomandibular joint function in patients with TMD, and thus improve the general conditions of the patient. Photo biomodulation, that is, the use of several light sources sometimes in the same device, can be used as a therapeutic resource [49]. Decreased pain and increased mandibular mobility in patients with TMD were also found after the use of LED photo biomodulation when applied to the masticatory muscles and points around TMJ. These results were achieved both with the use of $880 \mathrm{~nm}$ infrared LEDs, energy density of $7 \mathrm{~J} / \mathrm{cm}^{2}$, and power of $(0.03 \mathrm{~W})$ [50], with $850 \pm 10 \mathrm{~nm}$, energy density $18 \mathrm{~J} / \mathrm{cm}^{2}$, and power of $150 \mathrm{~mW}$; as well as the use of red LED $630 \pm 10 \mathrm{~nm}, 18$ $\mathrm{J} / \mathrm{cm}^{2}$, and power of $150 \mathrm{~mW}$. The effectiveness of photo biomodulation as in the treatment of TMD has been proven by several authors [50-53] but there are few controlled clinical studies analyzing the performance of photo biomodulation with different LED wavelengths in the same device with several simultaneous irradiation points in patients with TMD. Pain and functional limitations are inherent to temporomandibular dysfunction, and studies indicate that $70 \%$ of the population is affected with at least one TMD signal. Medications are commonly used to treat the pain, but they have a high cost and potential side effects, especially in the administration of NSAIDs and long-term use [41, 54]. Therefore, there is a need for studies that evaluate the use of non-pharmacological methods for the treatment of this dysfunction. Phototherapy has the potential to reduce pain and improve temporomandibular joint function in TMD patients, with consequent improvement in their quality of life. Photo biomodulation and LED therapy are treatment options for reduction of the inflammatory process and pain, besides inducing the regeneration of the target tissue $[54,55]$. The efficacy of phototherapy for the treatment of TMD has been proven by several authors [41, 56-60] but there are few controlled clinical studies comparing photo biomodulation performance with LED therapy in patients with TMDs. The American Academy of Craniomandibular Disorders has cited physical therapy as an important treatment heat, electrophysical modalities like transcutaneous electric neural stimulation, acupuncture and LLLT. (Kulekcioglu et al., 2003) [61] showed that, after 15 sessions of LLLT, TMD of both myogenic and erythrogenic causes responded to therapy with a significant reduction in pain, improvement in mouth opening and lateral motion, and a diminished number of 
Ahmad Khaled Alhakim et al; Sch J App Med Sci, Jan, 2022; 10(1): 9-14

trigger points. (Etiner C et al., 2006) [62] expressed similar results in 24 patients after 10 sessions of LLLT. Improved outcome of TMJDs laser therapy was documented by Santos et al., [63] who was applying LLLT at a comparatively higher dose. However, those patients had relief of symptoms during the treatment regimen. The main drawback of the procedure was that it had to be done at multiple sessions. Wertz reported that in many of studies related to the efficacy of LLLT, analysis uncovered one or more reasons for the negative findings reported, the most common being the use of extremely low doses [64].

\section{CONCLUSiON}

Low level laser therapy can be considered as an alternative physical modality in the management of myogenic Temporomandibular Disorder. Limitation of using Low level laser therapy clinically making using it should be with selected criteria and in cases. it is difficult to compare the different studies due to the great variability of the studied variables and the selected laser parameters.

\section{REFERENCES}

1. LeResche, L. (1997). Epidemiology of temporomandibular disorders: implications for the investigation of etiologic factors. Critical Reviews in Oral Biology \& Medicine, 8(3), 291-305.

2. Schiffman, E., Ohrbach, R., Truelove, E., Look, J., Anderson, G., Goulet, J. P., ... \& Svensson, P. (2014). Diagnostic criteria for temporomandibular disorders (DC/TMD) for clinical and research applications: recommendations of the International RDC/TMD Consortium Network and Orofacial Pain Special Interest Group. Journal of oral \& facial pain and headache, 28(1), 6-27.

3. LeResche, L., \& Von Korff, M. R. (1992). Research diagnostic criteria for temporomandibular disorders: review, criteria, examinations and specifications, critique. $J$ craniomandib Disord, 6(4), 301-355.

4. Von Korff, M., Dworkin, S. F., Le Resche, L., \& Kruger, A. (1988). An epidemiologic comparison of pain complaints. Pain, 32(2), 173-183.

5. Costen, J. B. (1934). Syndrome of ear and sinus symptoms dependent upon functions of the temporomandibular joint, Ann Otol Rhinol Laryngol, 3, 1-4.

6. Brussell, I. J. (1949). Temporomandibular joint diseases: differential diagnosis and treatment. The Journal of the American Dental Association, 39(5), 532-554.

7. Harvey, W. (1948). Investigation and survey of malocclusion and ear symptoms, with particular reference to otitic barotrauma; pain in ears due to change in altitude. British dental journal, 85(10), 219.

8. Moyers, R. E. (1950). An electromyographic analysis of certain muscles involved in temporomandibular movement. American journal of orthodontics, 36(7), 481-515.

9. Perry, H. T., \& Harris, S. C. (1954). Role of the neuromuscular system in functional activity of the mandible. The Journal of the American Dental Association, 48(6), 665-673.

10. Jarabak, J. R. (1956). An electromyographic analysis of muscular and temporomandibular joint disturbances due to imbalances in occlusion. The Angle Orthodontist, 26(3), 170-190.

11. Drangsholt, M. (1999). Temporomandibular Pain. In: Crombie, I., Croft, P., \& Linton, S., (eds) Epidemiology of pain. Seattle: IASP Press, pp.203234.

12. Macfarlane, T. V., Glenny, A. M., \& Worthington, H. V. (2001). Systematic review of populationbased epidemiological studies of oro-facial pain. Journal of dentistry, 29(7), 451-467.

13. Nilsson, I. M., List, T., \& Drangsholt, M. (2007). Incidence and temporal patterns of temporomandibular disorder pain among Swedish adolescents. Journal of orofacial pain, 21(2), 127132.

14. Slade, G. D., Bair, E., Greenspan, J. D., Dubner, R., Fillingim, R. B., Diatchenko, L., ... \& Ohrbach, R. (2013). Signs and symptoms of first-onset TMD and sociodemographic predictors of its development: the OPPERA prospective cohort study. The Journal of Pain, 14(12), T20-T32.

15. LeResche, L., Mancl, L. A., Drangsholt, M. T., Huang, G., \& Von Korff, M. (2007). Predictors of onset of facial pain and temporomandibular disorders in early adolescence. Pain, 129(3), 269278.

16. Nilsson, I. M., List, T., \& Drangsholt, M. (2005). Prevalence of temporomandibular pain and subsequent dental treatment in Swedish adolescents. Journal of orofacial pain, 19(2), 144150.

17. Slade, G. D., Ohrbach, R., Greenspan, J. D., Fillingim, R. B., Bair, E., Sanders, A. E., ... \& Maixner, W. (2016). Painful temporomandibular disorder: decade of discovery from OPPERA studies. Journal of dental research, 95(10), 10841092.

18. Nilsson, I. M., \& List, T. (2016). 10-year longitudinal follow-up of 2,255 adolescents screened for TMD pain. Int Ass Dent Res, Seoul; abstr nr 1458.

19. Mester, A. (2013). Laser biostimulation. Photomedicine and laser surgery, 31(6), 237-239.

20. Mester, E., Mester, A. F., \& Mester, A. (1985). The biomedical effects of laser application. Lasers Surg Med, 5, 31-39.

21. Carroll, J. D., Milward, M. R., Cooper, P. R., Hadis, M., \& Palin, W. M. (2014). Developments in low level light therapy (LLLT) for dentistry. Dental Materials, 30(5), 465-475. 
Ahmad Khaled Alhakim et al; Sch J App Med Sci, Jan, 2022; 10(1): 9-14

22. Karu, T. I. (2008). Mitochondrial signaling in mammalian cells activated by red and near-IR radiation. Photochemistry and photobiology, 84(5), 1091-1099.

23. Karu, T. (2010). Mitochondrial mechanisms of photobiomodulation in context of new data about multiple roles of ATP. Photomedicine and laser surgery, 28(2), 159-160.

24. Palacios-Callender, M., Quintero, M., Hollis, V. S., Springett, R. J., \& Moncada, S. (2004). Endogenous NO regulates superoxide production at low oxygen concentrations by modifying the redox state of cytochrome c oxidase. Proceedings of the National Academy of Sciences, 101(20), 76307635.

25. Cleeter, M. W. J., Cooper, J. M., Darley-Usmar, V. M., Moncada, S. A., \& Schapira, A. H. V. (1994). Reversible inhibition of cytochrome c oxidase, the terminal enzyme of the mitochondrial respiratory chain, by nitric oxide: implications for neurodegenerative diseases. FEBS letters, 345(1), 50-54.

26. Antunes, F., Boveris, A., \& Cadenas, E. (2004). On the mechanism and biology of cytochrome oxidase inhibition by nitric oxide. Proceedings of the National Academy of Sciences, 101(48), 1677416779.

27. Galkin, A., Higgs, A., \& Moncada, S. (2007). Nitric oxide and hypoxia. Essays in biochemistry, 43, 29-42.

28. Bolanos, J. P., Peuchen, S., Heales, S. J. R., Land, J. M., \& Clark, J. B. (1994). Nitric oxide-mediated inhibition of the mitochondrial respiratory chain in cultured astrocytes. Journal of neurochemistry, 63(3), 910-916.

29. Suresh, S., Merugu, S., \& Mithradas, N. (2015). Low-level laser therapy: A biostimulation therapy in periodontics. SRM Journal of Research in Dental Sciences, 6(1), 53.

30. Convissar, R. A. (2015). Principles and Practice of Laser Dentistry-E-Book. Elsevier Health Sciences.

31. Montesinos, M. (1988). Experimental effects of low power laser in encephalin and endorphin synthesis. J Eur Med Laser Assoc, 1(3), 2-6.

32. Jimbo, K., Noda, K., Suzuki, K., \& Yoda, K. (1998). Suppressive effects of low-power laser irradiation on bradykinin evoked action potentials in cultured murine dorsal root ganglion cells. Neuroscience letters, 240(2), 93-96.

33. Coker, J. G., \& Duker, J. S. (1996). Macular disease and optical coherence tomography. Current opinion in ophthalmology, 7(3), 33-38.

34. Lim, W., Lee, S., Kim, I., Chung, M., Kim, M., Lim, H., .. \& Choi, H. (2007). The antiinflammatory mechanism of $635 \mathrm{~nm}$ light-emittingdiode irradiation compared with existing $\mathrm{COX}$ inhibitors. Lasers in Surgery and Medicine: The Official Journal of the American Society for Laser Medicine and Surgery, 39(7), 614-621.
35. Bjordal, J. M., Lopes-Martins, R. A. B., \& Iversen, V. V. (2006). A randomised, placebo controlled trial of low level laser therapy for activated Achilles tendinitis with microdialysis measurement of peritendinous prostaglandin E2 concentrations. British journal of sports medicine, 40(1), 76-80.

36. Castano, A. P., Dai, T., Yaroslavsky, I., Cohen, R., Apruzzese, W. A., Smotrich, M. H., \& Hamblin, M. R. (2007). Low-level laser therapy for zymosan-induced arthritis in rats: Importance of illumination time. Lasers in Surgery and Medicine: The Official Journal of the American Society for Laser Medicine and Surgery, 39(6), 543-550.

37. Fikáčková, H., Dostálová, T., Vošická, R., Peterova, V., Navratil, L., \& Lesak, J. (2006). Arthralgia of the temporomandibular joint and lowlevel laser therapy. Photomedicine and Laser Therapy, 24(4), 522-527.

38. De Medeiros, J. S., Vieira, G. F., \& Nishimura, P. Y. (2005). Laser application effects on the bite strength of the masseter muscle, as an orofacial pain treatment. Photomedicine and Laser Therapy, 23(4), 373-376.

39. Farina, C. G., Duarte, M., \& Mori, M. (2005). Effects of low-intensity laser therapy $(780 \mathrm{~nm})$ in temporomandibular disorders: electromyographic, pain and bite force analysis (abstract). 5th Congress of World Association for Laser Therapy, 2004, São Paulo. Photomed Laser Surg, 23(1).

40. De Abreu Venancio, R., Camparis, C. M., \& De Fátima Zanirato Lizarelli, R. (2005). Low intensity laser therapy in the treatment of temporomandibular disorders: a double-blind study. Journal of oral rehabilitation, 32(11), 800807.

41. Graciele Carrasco, T., Oliveira Mazzetto, M., Galli Mazzetto, R., \& Mestriner, W. (2008). Low intensity laser therapy in temporomandibular disorder: a phase II double-blind study. Cranio ${ }^{\circ}, 26(4), 274-281$.

42. Sayed, N., Murugavel, C., \& Gnanam, A. (2014). Management of temporomandibular disorders with low level laser therapy. Journal of maxillofacial and oral surgery, 13(4), 444-450.

43. Kulekcioglu, S., Sivrioglu, K., Ozcan, O., \& Parlak, M. (2003). Effectiveness of low-level laser therapy in temporomandibular disorder. Scandinavian journal of rheumatology, 32(2), 114-118.

44. Esshagh Lassemia, Seyed Mehdi Jafarib, Mohammad Hosein Kalantar Motamedic, Fina Navid, Reza Lasemie .Low-level Laser Therapy in the Management of Temporomandibular Joint Disorder .J Oral Laser Applications 2008; 8: 83-86.

45. De Carli, M. L., Guerra, M. B., Nunes, T. B., Di Matteo, R. C., De Luca, C. E. P., Aranha, A. C. C., ... \& Witzel, A. L. (2013). Piroxicam and laser phototherapy in the treatment of TMJ arthralgia: A 
Ahmad Khaled Alhakim et al; Sch J App Med Sci, Jan, 2022; 10(1): 9-14

double-blind randomised controlled trial. Journal of oral rehabilitation, 40(3), 171-178.

46. Reisine, S. T., Fertig, J., Weber, J., \& Leder, S. (1989). Impact of dental conditions on patients' quality of life. Community dentistry and oral epidemiology, 17(1), 7-10.

47. De Abreu Venancio, R., Camparis, C. M., \& De Fátima Zanirato Lizarelli, R. (2005). Low intensity laser therapy in the treatment of temporomandibular disorders: a double-blind study. Journal of oral rehabilitation, 32(11), 800807.

48. Carvalho, C. M., de Lacerda, J. A., dos Santos Neto, F. P., Cangussu, M. C. T., Marques, A. M., \& Pinheiro, A. L. (2010). Wavelength effect in temporomandibular joint pain: a clinical experience. Lasers in medical science, 25(2), 229232.

49. Karu, T. I., Pyatibrat, L. V., \& Ryabykh, T. P. (2003). Melatonin modulates the action of near infrared radiation on cell adhesion. Journal of pineal research, 34(3), 167-172.

50. Costa, D. R., Costa, D. R., Pessoa, D. R., Masulo, L. J., Lo Schiavo Arisawa, E. A., \& Nicolau, R. A. (2017). Effect of LED therapy on temporomandibular disorder: a case study. Scientia Medica, 27(2).

51. Herpich, C. M., Leal-Junior, E. C. P., Gomes, C. A. F. D. P., Gloria, I. P. D. S., Amaral, A. P., Amaral, M. D. F. D. R. S., ... \& Biasotto-Gonzalez, D. A. (2018). Immediate and short-term effects of phototherapy on pain, muscle activity, and joint mobility in women with temporomandibular disorder: a randomized, double-blind, placebocontrolled, clinical trial. Disability and rehabilitation, 40(19), 2318-2324.

52. Magri, L. V., Carvalho, V. A., Rodrigues, F. C. C., Bataglion, C., \& Leite-Panissi, C. R. A. (2018). Non-specific effects and clusters of women with painful TMD responders and non-responders to LLLT: double-blind randomized clinical trial. Lasers in medical science, 33(2), 385-392.

53. Ahrari, F., Madani, A. S., Ghafouri, Z. S., \& Tunér, J. (2014). The efficacy of low-level laser therapy for the treatment of myogenous temporomandibular joint disorder. Lasers in medical science, 29(2), 551-557.

54. Mazzetto, M. O., Hotta, T. H., \& Pizzo, R. C. D. A. (2010). Measurements of jaw movements and TMJ pain intensity in patients treated with GaAlAs laser. Brazilian dental journal, 21, 356-360.

55. Gynther, G. W., Dijkgraaf, L. C., Reinholt, F. P., Holmlund, A. B., Liem, R. S., \& de Bont, L. G. (1998). Synovial inflammation in arthroscopically obtained biopsy specimens from the temporomandibular joint: a review of the literature and a proposed histologic grading system. Journal of oral and maxillofacial surgery, 56(11), 12811286.

56. Dostolová, T., Hlinakova, P., Kasparova, M., Rehacek, A., Vavrichova, L., \& Navratil, L. (2012). Effectiveness of physiotherapy disorders and GaAIAs laser in the management of temporomandibular joint. Photomed Laser Surg, 30(5), 275-80.

57. Pereira, T. S., Flecha, O. D., Guimarães, R. C., Oliveira, D. D. D., Botelho, A. M., Glória, J. C. R., \& Tavano, K. T. A. (2014). Efficacy of red and infrared lasers in treatment of temporomandibular disorders - a double-blind, randomized, parallel clinical trial. Cranio ${ }^{\circledR}, 32(1)$, 51-56.

58. Panhoca, V. H., Lizarelli, R. D. F. Z., Nunez, S. C., de Andrade Pizzo, R. C., Grecco, C., Paolillo, F. R., \& Bagnato, V. S. (2015). Comparative clinical study of light analgesic effect on temporomandibular disorder (TMD) using red and infrared led therapy. Lasers in medical science, 30(2), 815-822.

59. Bjordal, J. M., Ljunggren, A. E., Klovning, A., \& Slørdal, L. (2004). Non-steroidal anti-inflammatory drugs, including cyclo-oxygenase-2 inhibitors, in osteoarthritic knee pain: meta-analysis of randomised placebo controlled trials. Bmj, 329(7478), 1317.

60. Bjordal, J. M., Johnson, M. I., Lopes-Martins, R. A., Bogen, B., Chow, R., \& Ljunggren, A. E. (2007). Short-term efficacy of physical interventions in osteoarthritic knee pain. A systematic review and meta-analysis of randomised placebo-controlled trials. BMC musculoskeletal disorders, 8(1), 1-14.

61. Kulekcioglu, S., Sivrioglu, K., Ozcan, O., \& Parlak, M. (2003). Effectiveness of low-level laser therapy in temporomandibular disorder. Scandinavian journal of rheumatology, 32(2), 114-118.

62. Çetiner, S., Kahraman, S. A., \& Yücetas, Ş. (2006). Evaluation of low-level laser therapy in the treatment of temporomandibular disorders. Photomedicine and Laser Therapy, 24(5), 637-641.

63. Santos, T. D. S., Piva, M. R., Ribeiro, M. H., Antunes, A. A., Melo, A. R., \& Silva, E. D. D. O. (2010). Lasertherapy efficacy in temporomandibular disorders: control study. Brazilian journal of otorhinolaryngology, 76, 294-299.

64. Wertz, R. L. (2006). Class IV high power laser therapy in physical medicine and rehabilitation. Dyn Chiropr, (24)23, 8. 